\title{
PENGUKURAN TINGKAT PENGENALAN PENGGUNA GAMES TERHADAP MUATAN BUDAYA INDONESIA PADA MOBILE GAME BERBASIS ANDROID (STUDI KASUS: DAKON, KARAPAN SAPI DAN TEMPLE $R U S H$ PRAMBANAN)
}

\section{THE MEASUREMENT OF GAME USERS RECOGNITION LEVELS TOWARD INDONESIAN CULTURE ON ANDROID- BASED MOBILE GAME (CASE STUDY: DAKON, KARAPAN SAPI DAN TEMPLE RUSH PRAMBANAN)}

\author{
${ }^{1}$ Dicky Hidayat, ${ }^{2}$ Siti Hajar Komariah \\ 1,2Program Studi Desain Komunikasi Visual, Fakultas Industri Kreatif, Telkom University \\ 1dicky@tcis.telkomuniversity.ac.id, ${ }^{2}$ sitihajarkomariah@telkomuniversity.ac.id
}

\begin{abstract}
Abstrak-Era informasi global menjadikan budaya asing dengan mudahnya masuk, mempengaruhi kebiasaan dan kehidupan masyarakat Indonesia khususnya generasi muda. Salah satu media yang datang dan mempengaruhi budaya anak muda adalah media game berbasis android. Untuk mencegah dan mengimbangi gencarnya penetrasi budaya asing melalui mobile game ini, para developer game lokal membuat dan mengembangkan mobile games berbasis android yang di dalamnya sarat muatan budaya asli Indonesia, diantaranya game Dakon, Temple Rush: Prambanan, dan Karapan Sapi. Identitas budaya Indonesia sudah dihadirkan dalam elemen tekstual berupa narasi atau gameplay dan elemen non-tekxtual berupa karakter, background, suara, dan animasi. Para pembuat dan pengembang game bermuatan budaya Indonesia ini berharap pengguna games dapat mengenal dan mengetahui budaya loka Indonesia yang terkandung di dalam game tersebut. Untuk mengetahui tingkat pengenalan para pengguna game tersebut terhadap budaya Indonesia yang ada dalam games, perlu dilakukan pengukuran. Tingkat pengenalan atau pengetahuan seseorang terhadap suatu objek dapat diukur dengan menggunakan metode kuantitatif. Pengukuran dilakukan dengan memberikan sejumlah pertanyaan dalam bentuk angket tentang objek pengetahuan yang akan diukur. Penilaian dilakukan dengan cara membandingkan jumlah skor jawaban dengan skor yang diharapkan (tertinggi). Pengukuran dalam penelitian ini dilakukan dengan menyebarkan angket kepada 30 responden penggunan game Dakon, Temple Rush Prambanan, dan Karapan Sapi untuk mengetahui tingkat pengetahuan mereka terhadap muatan budaya asli Indonesia yang ada di dalamnya. Hasil dari pengukuran menunjukkan tingkat pengenalan atau pengetahuan para pengguna game terhadap muatan budaya Indonesia pada ketiga mobile games berbasis android tersebut (Dakon, Temple Rush: Prambanan, dan Karapan Sapi) adalah sebesar 75,17\% atau berada dalam kategori cukup.
\end{abstract}

Kata Kunci: Tingkat Pengetahuan, Identitas Budaya, Mobile Game
Abstract--The global information era makes foreign culture easy to enter and influence the habits and life of Indonesian people, especially the younger generation. One of the many media that come and influence the culture of young people is the android-based game media. To prevent and counterbalance the influx of foreign cultures through this mobile game, local game developers develop mobile android-based games that are loaded with original Indonesian cultural content, including Dakon games, Temple Rush: Prambanan, and Karapan Sapi. Indonesian cultural identity has been presented in textual elements in the form of narration or gameplay and non-textual elements of characters, background, sound, and animation. Game makers and developers hope users can know the game and recognize the local culture of Indonesia that contained in the game. To know the recognition levels of the game users to the culture of Indonesia that exist in the games, it needs to be measured. The level of recognition or knowledge of a person on an object can be measured by using quantitative methods. The measurement is done by giving a number of questions in the form of a questionnaire about the object of knowledge to be measured. Assessment is done by comparing the total score of answers with the expected score (highest). Measurements in this study were conducted by distributing questionnaires to 30 respondents who played the Dakon games, Temple Rush Prambanan, and Karapan Sapi. The results of the measurements indicate that the level of recognition or knowledge of game users on the content of Indonesian culture on the three mobile-based android games is equal to $75.17 \%$ or in enough category.

Keywords: Level of Knowledge, Cultural Identity, Mobile Game

\section{PENDAHULUAN}

Pengaruh budaya asing sedikit demi sedikit sudah mengikis budaya lokal dan nasional generasi muda 
Indonesia. Proses ini terjadi melalui berbagai macam media dan cara yang secara langsung atau tidak langsung ditonton, digunakan [1][2], bahkan dikonsumsi oleh kalangan muda di Indonesia. Era informasi global menjadikan budaya asing dengan mudahnya masuk dan mempengaruhi kebiasaan dan kehidupan masyarakat Indonesia khususnya generasi muda. Salah satu media yang banyak datang dan mempengaruhi budaya anak muda adalah media game berbasis android. Banyak game-game dari luar yang karakter dan tokohnya membawa budaya mereka di adopsi, dimainkan, bahkan dipraktekan dalam kehidupan sehari-hari oleh para pengguananya yang notabene adalah generasi muda kita.

Untuk mencegah dan mengimbangi gencarnya penetrasi budaya asing melalui mobile game ini, para developer game lokal yang masih mempunyai semangat nasionalisme, membuat dan mengembangkan mobile games berbasis android yang di dalamnya sarat muatan budaya asli Indonesia [2]. Identitas budaya Indonesia sudah dihadirkan dalam elemen tekstual berupa narasi atau gameplay dan elemen non-tekxtual berupa karakter, background, suara, dan animasi. Program ini dikembangkan dengan harapan budaya Indonesia bisa disebarkan dan dikenali oleh para pengguna games terutama generasi muda Indonesia sehingga kebanggaan akan budaya dan jati diri asli Indonesia bisa terus tumbuh dan terpelihara.

Ada 3 game bermuatan budaya Indonesia yang dijadikan objek dalam penelitian ini, yaitu game Dakon, Temple Rush: Prambanan, dan Karapan Sapi.

Game Dakon merupakan game yang diadaptasi dari permainan tradisional Indonesia yaitu congkak. Permainan tradisional ini berasal dari Jawa [2]. Di beberapa daerah di Indonesia permainan dakon ini dikenal juga tetapi dengan nama-nama yang berbeda, misalnya di Lampung dikenal dengan nama Dentuman Lamban, di Sulawesi dikenal dengan nama Mokaotan, Maggaleceng, Aggalacang atau Nogarata, dan di Kalimantan Selatan di kenal dengan sebutan Dakuan. Selain di Indonesia, permainan Dakon ini juga di kenal di beberapa negara Asia Tenggara dengan istilah yang berbeda, yaitu Sungka di Filipina dan Congkak di Malaysia. Secara umum, permainan Dakon ini dikenal dengan nama Mancala.

Game Karapan Sapi ini diadaptasi dari lomba pacu sapi yang berasal dari Madura. Lomba tersebut kini bisa dimainkan pada smartphone. Seperangkat perlengkapan kayu pengikat sapi, tempat berdiri pembalap, dan pembalap berpakaian khas madura lengkap dengan pecut kalelesnya coba diadaptasi dalam game ini. Sebagaimana lomba karapan sapi, dalam permainan ini terdapat saingan yang harus pemain kalahkan. Permainan game ini cukup sederhana, pemain cukup swipe dari bawah ke atas untuk menggerakan sapi sampai garis finish. Pada level-level berikutnya terdapat halangan berupa air, ayam, dan orang (petani) sebagai penghambat laju sapi.

GameTemple Rush Prambanan ini mengangkat legenda candi prambanan dimana sang tokoh Bandung Bondowoso dengan pakaian khas kerajaan Jawa (muncul dalam cover game di awal game) harus menyelesaikan seribu candi dalam satu malam untuk bisa menikahi wanita impiannya yaitu Nyi Loro Jongkrang. Untuk bisa menyelesaikan hal tersebut, maka ia menggunakan bantuan dari makhluk gaib berupa jin. Di game ini, pemain mengomando berbagai jenis jin dengan mengklik objek untuk menyelesaikan candi-candi tersebut. Nuansa etnis Indonesia pun terasa sangat kental dari musik pengiringnya yang menggunakan suara gamelan.

Para pengembang ketiga mobile game berbasis android dengan muatan budaya Indonesia di dalamnya ini, mempunyai tujuan mulia yaitu dikenalnya budaya Indonesia oleh para pengguna games setelah game ini dipelajari dan dimainkan. Penelitian sebelumnya sudah memetakan kandungan muatan budaya Indonesia yang ada dalam ketiga game tersebut, baik secara tekstual maupun non-tekstual, tetapi belum melakukan pengukuran tingkat keberhasilan proses pengenalan budaya terhadap penggunanya. Oleh karena itu, penelitian ini dilakukan untuk mengetahui tingkat keberhasilan proses pengenalan budaya Indonesia melalui media game. Tingkat pengenalan para pengguna games terhadap muatan budaya yang terkandung pada game yang sudah dimainkannya akan diteliti dan diukur dengan menggunakan pendekatan matematis.

Tingkat pengenalan atau pengetahuan seseorang terhadap suatu objek dapat diukur dengan menggunakan metode kuantitatif. Pengukuran dilakukan dengan memberikan sejumlah pertanyaan dalam bentuk angket tentang objek pengetahuan yang mau diukur, selanjutnya dilakukan penilaian dimana setiap jawaban benar dari masing-masing pertanyaan diberi nilai 1 dan jika salah diberi nilai 0 . Penilaian dilakukan dengan cara membandingkan jumlah skor jawaban dengan skor yang diharapkan (tertinggi). Pengukuran dalam penelitian ini dilakukan dengan menyebarkan angket kepada 30 responden penggunan game Dakon, Temple Rush Prambanan, dan Karapan Sapi untuk mengetahui tingkat pengetahuan mereka terhadap muatan budaya asli Indonesia yang ada di dalamnya.

Luaran dari penelitian ini berupa tingkat pengenalan dan pengetahuan para pengguna ketiga game terhadap nilai-nilai budaya Indonesia khususnya yang dikenalkan dalam ketiga game tersebut. Hasil dari penelitian dapat dimanfaatkan sebagai masukan bagi para pengembang game untuk lebih kreatif lagi dalam menyampaikan identitas budaya Indonesia berbasis game kepada generasi muda.

\section{STUDILITERATUR}

\section{A. Identitas Budaya}

Identitas berarti kondisi atau kenyataan tentang sesuatu yang sama, suatu keadaan yang mirip satu sama lain. (Webster New World Dictionary)

Definisi kebudayaan menurut Koentjaraningrat [3] adalah keseluruhan sistem gagasan, tindakan dan hasil karya manusia dalam rangka kehidupan masyarakat yang dijadikan milik diri manusia dengan belajar. 
Identitas budaya merupakan ciri yang ditunjukkan seseorang karena orang itu merupakan anggota dari sebuah kelompok etnik tertentu. Itu meliputi pembelajaran tentang dan penerimaan tradisi, sifat bawaan, bahasa, agama, keturunan dari suatu kebudayaan [4]. Dalam arti yang sederhana, identitas budaya adalah rincian karakteristik atau ciri-ciri sebuah kebudayaan yang dimiliki oleh sekelompok orang yang kita ketahui batas-batasnya jika dibandingkan dengan karakteristik atau ciri-ciri kebudayaan orang lain [4].

\section{B. Video Game Berbasis Android Sebagai Media Pembelajaran}

Video game adalah bentuk permainan yang memberikan informasi secara virtual, mempunyai aturan dan alur cerita, memberikan tantangan, bersifat interaktif serta dimainkan dengan memanipulasi gambar pada layar [5]. Industri game dewasa ini berkembang semakin pesat, siapapun kini dapat memainkan game dalam berbagai macam platform, mulai dari PC, console, hingga ponsel. Game yang pada awalnya hanya dimanfaatkan untuk sekedar pengisi waktu luang, kini juga digunakan untuk kebutuhan bisnis, militer, olah raga, pendidikan, dan lainlain.

Android adalah sistem operasi berbasis Linux, berlisensi Apache dan bersifat open source. Android dirancang untuk perangkat seluler dengan touch screen. User interface pada Android didasarkan pada manipulasi langsung, menggunakan masukan sentuh yang serupa dengan tindakan di dunia nyata, seperti menggesek, mengetuk, mencubit, dan membalikkan cubitan untuk memanipulasi obyek di layar.

Game berbasis android adalah permainan digital yang dikembangkan umumnya berbasis java++ program sehingga kompatibel untuk dimainkan dalam smartphone atau tablet dengan versi dan seri tertentu.

Game merupakan salah satu kegiatan yang dapat menarik perhatian siapapun baik itu anak kecil, remaja bahkan orang yang sudah dewasa, bahkan game merupakan potential learning environment, atau sebuah literatur baru dalam pendidikan bahkan game dapat memberikan manfaat yang cukup banyak, meskipun hal tersebut tergantung pada jenis atau ragam permainan [1]. Banyak alasan mengapa game begitu digemari. Gee [5] menyebutkan beberapa alasan mengapa seseorang bermain game yaitu kepuasan menyelesaikan tugas, mengatasi rintangan dan tantangan, hiburan, fantasi yang baru, interaksi dengan teman dan keluarga serta rasa ingin tahu. Pendapat ini menunjukkan bahwa game memiliki dampak yang tidak selalu buruk. Banyak penelitian memaparkan pengaruh buruk game terhadap performa belajar, game dianggap memberi andil terhadap tumbuhnya sifat asosial, namun game juga memiliki sisi baik, terutama jika dipergunakan sebagai sarana pembelajaran [1].

Konten dan informasi pendidikan dapat disampaikan melalui game kepada pengguna melalui dua cara, yaitu [6]:
- Textual, yaitu pengguna mendapatkan penjelasan tentang situasi tertentu melalui teks, narasi, dan gameplay

- Non-Textual, yaitu informasi pendidikan disampaikan pada pengguna secara grafis melalui gambar, karakter, suara dan animasi.

\section{Konsep Pengetahuan}

Pengetahuan adalah merupakan hasil dari tahu dan ini setelah orang melakukan penginderaan terhadap obyek tertentu. Penginderaan terjadi melalui panca indera manusia, yakni indera penglihatan, pendengaran, penciuman, rasa dan raba. Sebagaian besar pengetahuan manusia diperoleh melalui mata dan telinga [2]. Pengetahuan atau kognitif merupakan domain yang sangat penting untuk terbentuknya tindakan seseorang (Overt Behaviour).

Menurut Notoatmodjo [7], ada beberapa faktor yang mempengaruhi pengetahuan seseorang, yaitu: pendidikan, media masa / media informasi, sosial budaya dan ekonomi, lingkungan, pengalaman, dan usia.

\section{Pengukuran Pengetahuan}

Pengukuran pengetahuan salah satunya dapat dilakukan dengan sistem angket. Sistem ini sederhana, tetapi dapat memberikan informasi tentang tingkat pengetahuan responden akan suatu objek. Responden diminta untuk menjawab beberapa pertanyaan tentang objek pengetahuan yang akan di ukur, diman penilaian untuk setiap pertanyaan yang dijawab benar diberi nilai 1 dan jika salah diberi nilai 0. Selanjutnya hasil total jawaban benar di bandingkan dengan nilai maksimum dan dikalikan $100 \%$. Penilaian dapat dilakukan dengan menggunakan persamaan 1 .

$$
N=\frac{S p}{S m} \times 100 \%
$$

Keterangan:

$\mathrm{N}=$ Nilai pengetahuan

$\mathrm{Sp}=$ Skor yang diperoleh

$\mathrm{Sm}=$ Skor maksimum

Misal: jumlah pertanyaan tentang suatu objek pengetahuan ada 100. Responden A menjawab dengan benar 60 pertanyaan, sehingga dengan menggunakan persamaan1, tingkat pengetahuan dari Responde A terhadap objek yang di ukur adalah:

$$
A=\frac{60}{100} \times 100 \%=60 \%
$$

Hasil perhitungan prosentase jawaban benar responden diinterpretasikan secara kualitatif dengan acuan sebagai berikut:

1. Baik : Nilai $=76-100 \%$

2. Cukup : Nilai $=56-75 \%$

3. Kurang : Nilai $=40-55 \%$

4. Tidak baik : Nilai $<40 \%$ 
Dalam pengukuran tingkat pengetahuan, jenis statistik deskriptif yang biasa digunakan adalah:

A. Persentase

$$
P=\frac{R x}{N} \times 100 \%
$$

Keterangan :

$\mathrm{P}=$ Persentase

$\mathrm{Rx}=$ Banyaknya responden dengan kriteria

tertentu

$\mathrm{N}=$ Jumlah total responden/ sampel

B. Rata-Rata

$$
\mu=\frac{X 1+X 2+\ldots+X N}{N}
$$

Keterangan:

$$
\begin{array}{ll}
\mu & =\text { Nilai rata-rata } \\
\mathrm{X} 1, \mathrm{X} 2, \ldots, \mathrm{XN} & =\text { Nilai Responden ke-1, 2,..,N } \\
\mathrm{N} & =\text { Jumlah Responden/ Sampel }
\end{array}
$$

\section{Median (Nilai Tengah)}

$$
\mathrm{Me}=\frac{\mathrm{N}+1}{2}
$$

Keterangan:

$$
\begin{array}{ll}
\mathrm{Me} & =\text { Median } \\
\mathrm{N} & =\text { Jumlah Responden/ Sampel }
\end{array}
$$

Nilai tengah diperoleh dengan mengurutkan data dari yang kecil ke besar dan selanjutnya melihat data nilai ke-x sesuai hasil perhitungan. Misal jika ada 11 data maka nilai tengah nya adalah data ke-6 setelah diurutkan. Jika ada 10 data, maka nilai tengahnya adalah nilai data ke-5 ditambah data ke-6 dibagi 2.

\section{METODOLOGI PENELITIAN}

\section{A. Jenis Penelitian}

Penelitian dilakukan untuk mengukur tingkat pengetahuan responden terhadap suatu hal dengan menggunakan pendekatan kuantitatif. Pendekatan ini dilakukan melalui langkah-langkah sebagai berikut:

1. Pemilihan sample yang akan menjadi responden penelitian. Target sampel adalah 30 responden pengguna ketiga game: Dakon, Te,ple Rush Prambanan, Karapan Sapi.

2. Pembuatan seperangkat set angket pertanyaan untuk mengukur tingkat pengenalan responden terhadap hal yang di ukur. Ada 8 pertanyaan yang diujikan ke 15 siswa. Dilakukan Uji validitas dan reliabilitas. Dari 8 pertanyaan dikembangkan lagi menjadi masingmasing 6 pertanyaan per kategori game sehingga total menjadi 18 pertanyaan. Angket berisi 18 pertanyaan ini di sebar kepada pengguna ketiga game: Dakon,
Temple Rush Prambanan, Karapan Sapi untuk memperoleh 30 sample.

3. Penilaian dengan memeriksa jawaban responden dibandingkan dengan standar jawaban dengan memberikan nilai 1 pada jawaban yang sesuai dan 0 (nol) pada jawaban yang tidak sesuai.

4. Penentuan skor per responden, rata-rata, dan per item kategori yang sudah ditentukan diawal dengan menggunakan persamaan 1, 2, dan 3 .

B. Obyek Penelitian

Obyek penelitian adalah para pengguna game yang sudah pernah memainkan ketiga game yaitu Dakon, Temple Rush Prambanan, dan Karapan sapi. Dari pengamatan di lapangan, pengguna ketiga game ini adalah siswa SD dan SMP. Sampel penelitian yang selanjutnya dijadikan responden adalah siswa SMP dengan mempertimbangkan beberapa hal:

1. Siswa SMP merupanan user yang cukup aktif dalam penggunaan mobile game

2. Tingkat pengetahuan smp lebih dibandingkan dengan kemampuan anak SD

3. Pengenalan budaya yang terkandung dalam game tersebut sudah mulai dipelajari dari SD sampai dengan SMP

4. Usia remaja rentan terpengaruh budaya luar dan melupan budaya sendiri

Target sampel pada penelitian ini 30 orang siswa, sehingga angket kuisioner/ pertanyaan disebar ke 50 siswa dan yang kembali dan diolah sebanyak 32 angket.

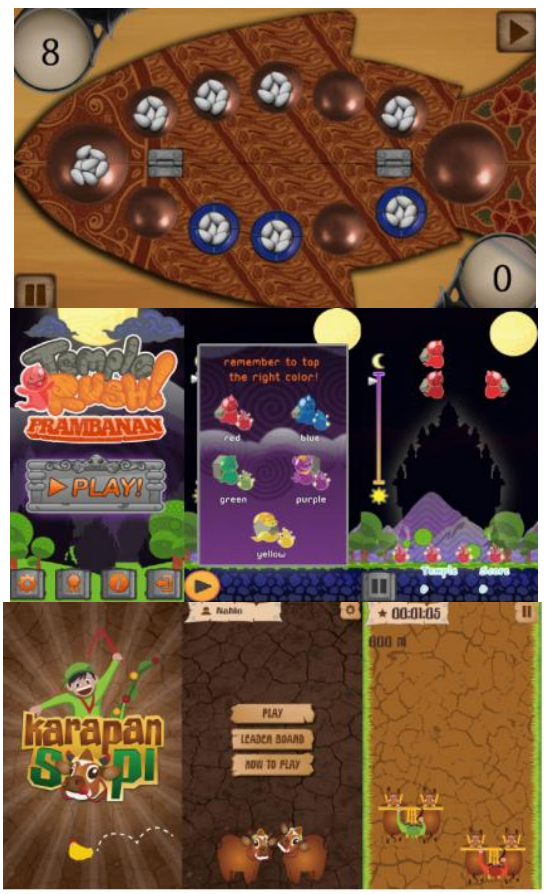

Gambar 1. Tampilan Game Dakon, Temple Rush Prambanan, dan Karapan Sapi 
Responden adalah siswa SMP kelas 7 dan kelas 8 yang pernah menggunakan dan memainkan ke-3 games, yaitu game Dakon, Temple Rush Prambanan dan Karapan Sapi. Siswa kelas 7 berjumlah 20 orang dari 32 orang, yang berarti $62,5 \%$ dan kelas 8 sebanyak 12 siswa orang atau $37,5 \%$.

\section{Uji Validitas dan Reliabilitas Data}

Angket kuisioner dengan sejumlah pertanyaan diujikan kepada 15 responden, dan hasil jawabannya diuji statistik untuk melihat valliditas dan reliabilitasnya. Hasil dari Uji validitas dapat dilihat pada Tabel 1 .

TABEL 1

HASIL UJI VALIDITAS

\begin{tabular}{|l|c|c|}
\hline \multicolumn{1}{|c|}{ Variabel } & r hitung & $\begin{array}{c}\text { Validitas } \\
\text { (r Tabel 0,3) }\end{array}$ \\
\hline $\begin{array}{l}\text { Berapa banyak pemain yang } \\
\text { dibutuhkan dalam permainan } \\
\text { Dakon ini? }\end{array}$ & 0.470457 & Valid \\
\hline $\begin{array}{l}\text { Dalam Permainan Dakon ini } \\
\text { unsur budaya Indonesia apa saja } \\
\text { yang anda lihat? }\end{array}$ & 0.788813 & Valid \\
\hline $\begin{array}{l}\text { Hewan apa yang kamu lihat dalam } \\
\text { permainan ini? }\end{array}$ & 0.686703 & Valid \\
\hline $\begin{array}{l}\text { Dalam Permainan Karapan Sapi } \\
\text { ini unsur budaya Indonesia apa } \\
\text { saja yang anda lihat? }\end{array}$ & 0.444083 & Valid \\
\hline $\begin{array}{l}\text { Peralatan apa yang digunakan } \\
\text { dalam permainan ini untuk } \\
\text { memacu sapi agar berlari } \\
\text { kencang? }\end{array}$ & 0.59186 & Valid \\
\hline $\begin{array}{l}\text { Karapan sapi adalah bagian } \\
\text { budaya Indonesia yang biasa } \\
\text { digunakan sebagai bentuk apa? }\end{array}$ & 0.474102 & Valid \\
\hline $\begin{array}{l}\text { Jenis musik apa yang anda dengar } \\
\text { dalam permainan ini? }\end{array}$ & 0.686523 & Valid \\
\hline $\begin{array}{l}\text { Candi adalah salah satu } \\
\text { peninggalan Budaya Indonesia } \\
\text { yang merupakan tempat ibadah } \\
\text { agama apa? }\end{array}$ & 0.812328 & Valid \\
\hline
\end{tabular}

Seluruh pertanyaan dinyatakan valid karena $r$ hitung lebih besar dari $r$ tabel. Uji reliabilitas data dapat dilihat pada Tabel 2.

TABEL 2.

HASIL UJI RELIABILITAS DATA

\begin{tabular}{|r|r|}
\hline $\begin{array}{c}\text { Cronbach's } \\
\text { Alpha }\end{array}$ & N of Items \\
\hline .768 & 8 \\
\hline
\end{tabular}

Dari hasil pengolahan, nilai cronbach alpha yang diperoleh $>$ dari 0,7 , sehingga data dapat dikatakan reliabel.

\section{Teknik Pengolahan Data}

Pengolahan data dilakukan dengan merekap hasil jawaban setiap responden terhadap keseluruhan pertanyaan yang diberikan. Dengan menggunakan persamaan 1 dihitung persentase pencapaian nilai setiap responden. Selanjutnya dengan menggunakan persamaan 2 dan persamaan 3 dihitung rata-rata pencapaian tingkat pengetahuan responden secara keseluruhan dan persentase tingkat pengetahuan responden per kategori game. Hasil dari pengukuran ini dijadikan dasar dalam melakukan proses analisa.

\section{HASIL DAN ANALISIS}

Hasil dari pengukuran tingkat pengenalan/ pengetahuan para pengguna games terhadap muatan budaya Indonesia yang ada pada games Dakon, Temple Rush Prambanan, dan Karapan Sapi dapat dilihat pada Tabel 3.

TABEL 3

Hasil Pengukuran TingKat Pengetahuan PengGuna Game terhadaP MUATAN BUDAYA INDONESIA

\begin{tabular}{|c|c|c|c|c|}
\hline $\begin{array}{l}\text { Respo } \\
\text { nden }\end{array}$ & $\begin{array}{l}\text { Tingkat } \\
\text { Pengetah } \\
\text { uan pada } \\
\text { Dakon }\end{array}$ & $\begin{array}{c}\text { Tingkat } \\
\text { Pengetahuan } \\
\text { pada Temple } \\
\text { Rush } \\
\text { Prambanan } \\
\end{array}$ & $\begin{array}{c}\text { Tingkat } \\
\text { Pengetahu } \\
\text { an pada } \\
\text { Karapan } \\
\text { Sapi } \\
\end{array}$ & $\begin{array}{c}\text { Tingkat } \\
\text { Pengetahuan } \\
\text { Secara } \\
\text { Keseluruhan }\end{array}$ \\
\hline $\mathrm{R} 1$ & $50.00 \%$ & $16.67 \%$ & $50.00 \%$ & $38.89 \%$ \\
\hline $\mathrm{R} 2$ & $66.67 \%$ & $66.67 \%$ & $33.33 \%$ & $55.56 \%$ \\
\hline R3 & $83.33 \%$ & $83.33 \%$ & $83.33 \%$ & $83.33 \%$ \\
\hline $\mathrm{R} 4$ & $83.33 \%$ & $66.67 \%$ & $33.33 \%$ & $61.11 \%$ \\
\hline R5 & $100.00 \%$ & $66.67 \%$ & $50.00 \%$ & $72.22 \%$ \\
\hline R6 & $66.67 \%$ & $33.33 \%$ & $16.67 \%$ & $38.89 \%$ \\
\hline R7 & $100.00 \%$ & $66.67 \%$ & $83.33 \%$ & $83.33 \%$ \\
\hline R8 & $66.67 \%$ & $33.33 \%$ & $33.33 \%$ & $44.44 \%$ \\
\hline R9 & $100.00 \%$ & $100.00 \%$ & $66.67 \%$ & $88.89 \%$ \\
\hline R10 & $83.33 \%$ & $100.00 \%$ & $83.33 \%$ & $88.89 \%$ \\
\hline R11 & $83.33 \%$ & $83.33 \%$ & $66.67 \%$ & $77.78 \%$ \\
\hline $\mathrm{R} 12$ & $83.33 \%$ & $33.33 \%$ & $50.00 \%$ & $55.56 \%$ \\
\hline R13 & $50.00 \%$ & $50.00 \%$ & $100.00 \%$ & $66.67 \%$ \\
\hline R14 & $66.67 \%$ & $50.00 \%$ & $83.33 \%$ & $66.67 \%$ \\
\hline $\mathrm{R} 15$ & $66.67 \%$ & $100.00 \%$ & $83.33 \%$ & $83.33 \%$ \\
\hline R16 & $66.67 \%$ & $50.00 \%$ & $83.33 \%$ & $66.67 \%$ \\
\hline $\mathrm{R} 17$ & $100.00 \%$ & $83.33 \%$ & $66.67 \%$ & $83.33 \%$ \\
\hline $\mathrm{R} 18$ & $83.33 \%$ & $83.33 \%$ & $50.00 \%$ & $72.22 \%$ \\
\hline R19 & $100.00 \%$ & $66.67 \%$ & $100.00 \%$ & $88.89 \%$ \\
\hline R20 & $83.33 \%$ & $83.33 \%$ & $83.33 \%$ & $83.33 \%$ \\
\hline $\mathrm{R} 21$ & $100.00 \%$ & $100.00 \%$ & $66.67 \%$ & $88.89 \%$ \\
\hline R22 & $100.00 \%$ & $100.00 \%$ & $83.33 \%$ & $94.44 \%$ \\
\hline $\mathrm{R} 23$ & $66.67 \%$ & $100.00 \%$ & $83.33 \%$ & $83.33 \%$ \\
\hline $\mathrm{R} 24$ & $83.33 \%$ & $100.00 \%$ & $83.33 \%$ & $88.89 \%$ \\
\hline $\mathrm{R} 25$ & $66.67 \%$ & $66.67 \%$ & $83.33 \%$ & $72.22 \%$ \\
\hline $\mathrm{R} 26$ & $100.00 \%$ & $83.33 \%$ & $83.33 \%$ & $88.89 \%$ \\
\hline $\mathrm{R} 27$ & $100.00 \%$ & $83.33 \%$ & $83.33 \%$ & $88.89 \%$ \\
\hline R28 & $50.00 \%$ & $33.33 \%$ & $66.67 \%$ & $50.00 \%$ \\
\hline R29 & $83.33 \%$ & $100.00 \%$ & $83.33 \%$ & $88.89 \%$ \\
\hline $\mathrm{R} 30$ & $83.33 \%$ & $100.00 \%$ & $83.33 \%$ & $88.89 \%$ \\
\hline R31 & $100.00 \%$ & $66.67 \%$ & $100.00 \%$ & $88.89 \%$ \\
\hline
\end{tabular}




\begin{tabular}{|l|c|r|r|r|}
\hline $\begin{array}{c}\text { Respo } \\
\text { nden }\end{array}$ & $\begin{array}{c}\text { Tingkat } \\
\text { Pengetah } \\
\text { uan pada } \\
\text { Dakon }\end{array}$ & $\begin{array}{c}\text { Tingkat } \\
\text { Pengetahuan } \\
\text { pada Temple } \\
\text { Rush } \\
\text { Prambanan }\end{array}$ & $\begin{array}{c}\text { Tingkat } \\
\text { Pengetahu } \\
\text { an pada } \\
\text { Karapan } \\
\text { Sapi }\end{array}$ & $\begin{array}{c}\text { Tingkat } \\
\text { Pengetahuan } \\
\text { Secara } \\
\text { Keseluruhan }\end{array}$ \\
\hline R32 & $83.33 \%$ & $83.33 \%$ & $83.33 \%$ & $83.33 \%$ \\
\hline $\begin{array}{l}\text { Rata- } \\
\text { Rata }\end{array}$ & $\mathbf{8 1 . 2 5 \%}$ & $\mathbf{7 2 . 9 2 \%}$ & $\mathbf{7 1 . 3 5 \%}$ & $\mathbf{7 5 . 1 7 \%}$ \\
\hline
\end{tabular}

Dari hasil pengukuran dapat dilihat, tingkat pengetahuan pengguna game terhadap adanya muatan budaya Indonesia dalam game Dakon yang tertinggi adalah $100 \%$ dan terendah adalah $50 \%$. Sementara itu, tingkat pengetahuan tertinggi terhadap adanya muatan budaya Indonesia dalam game Temple Rush Prambanan adalah $100 \%$ dan terendah adalah $16,67 \%$. Sama dengan yang terjadi pada kedua game, pada game Karapan Sapi, tingkat pengetahuan pengguna game terhadap adanya muatan budaya Indonesia dalam game tersebut juga mencapai $100 \%$ dan yang terendah adalah $16,67 \%$.

Tingkat pengetahuan pengguna game secara keseluruhan terhadap adanya muatan budaya Indonesia dalam ketiga game tersebut, yang tertinggi adalah $94,44 \%$ dan yang terendah adalah $38,89 \%$.

Hasil ini menunjukkan bahawa tingkat pengenalan dan pengetahuan para pengguna game terhadap adanya muatan budaya Indonesia dalam ktiga game Dakon, Temple Rush Prambanan, dan Karapan Sapi berada pada kategori cukup. Hal ini ditunjukkan dengan nilai tingkat pengetahuan ratarata yang diperoleh adalah $75,17 \%$. Jika dibandingkan dari ketiga game yang diteliti, Dakon lebih dikenal luas oleh para pengguna game sebagai game dengan muatan budaya lokal Indonesia di dalamnya dibandingkan dengan kedua game lainnya. Hal ini ditunjukkan oleh hasil pengukuran tingkat pengenalan para pengguna game terhadap muatan budaya Indonesia pada game Dakon memperoleh rata-rata nilai dalam kategori baik yaitu $81,25 \%$. Sedangkan kedua game lainnya, tingkat pengenalan para pengguna terhadap muatan budaya Indonesia dalam kedua game tersebut berada dalam kategori cukup, dengan perolehan nilai ratarata masing-masing 72,92\% untuk game Temple Rush Prambanan dan 71,35\% untuk game Karapan Sapi.

Meskipun sudah cukup dikenal muatan budaya Indonesia dalam sebuah game lokal, tingkat pengetahuan pengguna game lebih terbantu oleh narasi sebelum game dimulai bukan pada inti permainannya sendiri. Hal ini menjadi pekerjaan rumah bagi para pengembang game untuk mengangkat tema game yang benar-benar dikenal, diminati, dan disukai oleh pengguna dengan tetap membawa muatan budaya lokal.

\section{KESIMPULAN}

Dari hasil pengolahan data, pengukuran, analisis dan kaitannya dengan teori, dapat diambil kesimpulan bahwa mobile game Dakon, Temple Rush: Prambanan, dan Karapan sapi sebagai game yang dibuat oleh pengembang game lokal sudah cukup berhasil mengenalkan identitas budaya Indonesia kepada para pengguna game, yang dihadirkan dalam bentuk Textual (narasi, teks, dan game play), dan elemen Non-Textual (karakter, background, musik, dan animasi). Hal ini dapat dilihat dari hasil pengukuran tingkat pengetahuan para pengguna game terhadap adanya muatan budaya Indonesia yang terkandung dalam ketiga game tersebut dengan kategori pengenalan berada pada kategori cukup, mendekati baik, yaitu memperoleh nilai $75,17 \%$.

\section{DAFTAR PUSTAKA}

[1] 5 Dumbleton, Tim \& Kirriemuir, John. Digital Game and Education, In Understanding Digital Game, Thaosand Oaks. CA., Sage, London (2006), pp. 225226.

[2] 7 Grodal, Torben. Stories for Eye, Ear and Muscle, In The Video Game: Theory Reader. Routledge, New York (2003).

[3] 9 Koentjaraningrat. Pengantar Ilmu Antropologi. Radar Jaya Offset, Jakarta, (2000).

[4] 10 Kusumohamidjojo, Budiono. Filsafat Kebudayaan, Jalasutra, Yogyakarta, (2009).

[5] 6 Gee, James Paul. Good Video Game and Good Learning, Peter Lang Publishing Inc., New York, (2007).

[6] 4 Daphne A. Jameson. Reconceptualizing Cultural Identity and Its Role, In Intercultural Business Communication, Sage Journals, International Journal of Business Comunication, London, (2007).

[7] 12 Notoatmodjo, S. Promosi Kesehatan dan Ilmu Perilaku. Cetakan I. Jakarta : PT. Rineka Cipta. (2007) 